Cite this article as: Cunha, D., \& Relvas, A. P. (2014). Pathological Gambling and Couple: Towards an Integrative Systemic Model. Journal of Gambling Studies, 30(2), 213-228. https://doi.org/10.1007/s10899-013-9366-9

\title{
Pathological Gambling and Couple: Towards an Integrative Systemic Model
}

\author{
Diana Cunha \\ Ana Paula Relvas
}

\begin{abstract}
This article is a critical literature review of pathological gambling focused in the family factors, particularly in the couple dynamics. Its main goal is to develop an explicative integrative systemic model of pathological gambling, based in these couple dynamics. To achieve that aim, a bibliography search was made, using on-line data bases (e.g., EBSCO Host) and recognized books in pathological gambling subject, as well as in the systemic approach in general. This process privileged the recent works (about $70 \%$ of the reviewed literature was published in the last decade), however, also considered some classic works (the oldest one dates back to 1970). The guiding focus of this literature search evolves according to the following steps: (1) search of general comprehension of pathological gambling (19 references), (2) search specification to the subject "pathological gambling and family" (24 references), (3) search specification to the subject "pathological gambling and couple"(11 references), (4) search of systemic information which integrates the evidence resulted in the previous steps (4 references). The developed model is constituted by different levels of systemic complexity (social context, family of origin, couple and individual) and explains the problem as a signal of perturbation in the marital subsystem vital functions (e.g., power and control) though the regularities of marital dynamics of pathological gamblers. Furthermore, it gives theoretical evidence of the systemic familiar intervention in the pathological gambling.
\end{abstract}

Keywords: Pathological gambling; Family; Couple; Regularities; Reciprocity

\section{Introduction}

Pathological gambling (PG) has been widely studied on an individual basis (Toneatto and Ladouceur 2003; Toneatto and Millar 2004), however, systemic explanatory and

\footnotetext{
Diana Cunha

Faculty of Psychology and Educational Sciences, University of Coimbra, Rua do Colégio Novo, Apartado 6153, 3001-802 Coimbra, Portugal | e-mail: diicunha@gmail.com

Faculty of Psychology and Educational Sciences, University of Coimbra, Rua do Colégio Novo, Apartado 6153, 3001-802 Coimbra, Portugal | e-mail: aprelvas@fpce.uc.pt
} 
interventional approaches to the problem are relatively scarce (Garrido et al. 2004; Oei and Raylu 2004). The literature has recognized the important role of family and, in particular, of couple dynamics in pathological gambling since the nineties and has strongly underlined these ideas in the last decade (Bertrand et al. 2008; Garrido et al. 2004; Lee 2009; McComb et al. 2009; Steinberg 1993). In addition, to justifying the emphasis of this work on the couple, it is important to note that this subsystem (marital) is generally the first to suffer the impact of PG (Montero and Megías-Lizancos 2011). The marital subsystem is regarded as having the most effect on individual life (Relvas 1996) and any changes in it (marital subsystem) have a huge influence on the other family systems (Garrido et al. 2004; Lee 2009). The present work arises from the need to clarify, organize and integrate the evidence from the literature on family dynamics and, in particular, on marital dynamics and their relationship to PG. This paper therefore aims to provide an explanatory, integrative, systemic model of pathological gambling, based on couple dynamics, through the evidence collected from a thorough literature review, focused on a systemic understanding of PG.

\section{Review Approach}

To satisfy the main aim of this work-to develop an explanatory, integrative, systemic model of pathological gambling - the literature search became more complex and specific as it progressed. Initially, the objective was to gain a broad understanding of pathological gambling (e.g. definition and historical development, degrees of severity, associated factors). Then, considering the importance that the literature on gambling ascribed to the family, the review focused on 'PG and Family'. After this, and once more thanks to the relevance given to it by the literature, the topic was again narrowed and the focus was on 'PG and Couple'. The last stage of the search involved coordinating the evidence garnered from the earlier stages, in a systematic comprehension of pathological gambling. This process concentrated on the recent works (about $70 \%$ of the reviewed literature was published in the last decade), but it also considered some classic ones (the oldest dates back to 1970) (Table 1). Online databases were accessed (e.g., EBSCO Host) and recognized books on pathological gambling were consulted, as well as on the systemic approach. As result of this search process, 19 references about the general comprehension of pathological gambling were selected, along with 24 references about "pathological gambling and family", 11 relating to "pathological gambling and couple" and, finally, 4 with systemic information which incorporates the evidence supplied by the previous steps (Table 1). Obviously, some of these references provided important information on more than one subject (for example, references about family, very often also clarify some aspects about the couple), however to simplify the categorization, it followed the central theme.

The structure of the paper reflects this methodological approach: (1) conceptual delimitation of PG (types and psychopathological status); (2) family relations of the pathological gambler and their reciprocal interaction with the problem, highlighting the marital subsystem; (3) development of a systemic model to account for PG, focusing on the couple.

\section{Earlier Systemic Models for PG}

Hammond (1997) proposed a systemic model based on Bateson's theory of relationships and particularly in his description of symmetrical systems. This model presents three 
Table 1 Brief characterization of the analyzed literature references

\begin{tabular}{|c|c|c|c|}
\hline References characteristics & $\begin{array}{l}\text { Frequencies } \\
(\mathrm{n} / \%)\end{array}$ & Type of work & $\begin{array}{l}\text { Frequencies } \\
(\mathrm{n} / \%)\end{array}$ \\
\hline \multicolumn{4}{|l|}{ Research steps } \\
\hline \multirow{3}{*}{$\begin{array}{l}\text { General comprehension of pathological } \\
\text { gambling }\end{array}$} & \multirow[t]{3}{*}{$21 / 35.0$} & Empirical study & $7 / 33.3$ \\
\hline & & Literature review & $5 / 23.8$ \\
\hline & & $\begin{array}{l}\text { Other (e.g., theoretical } \\
\text { model; diagnosis manual) }\end{array}$ & $9 / 42.9$ \\
\hline \multirow[t]{3}{*}{ Pathological gambling and family } & \multirow[t]{3}{*}{$24 / 40.0$} & Empirical study & $14 / 58.3$ \\
\hline & & Literature review & $7 / 29.2$ \\
\hline & & $\begin{array}{l}\text { Other (e.g., theoretical } \\
\text { model; diagnosis manual) }\end{array}$ & $3 / 12.5$ \\
\hline \multirow[t]{3}{*}{ Pathological gambling and couple } & \multirow[t]{3}{*}{$11 / 18.3$} & Empirical study & $8 / 72.7$ \\
\hline & & Literature review & $1 / 9.1$ \\
\hline & & $\begin{array}{l}\text { Other (e.g., theoretical } \\
\text { model; diagnosis manual) }\end{array}$ & $2 / 18.2$ \\
\hline \multirow{3}{*}{$\begin{array}{l}\text { Systemic information which integrates the } \\
\text { evidence resulted in the previous steps }\end{array}$} & \multirow[t]{3}{*}{$4 / 6.7$} & Empirical study & $0 / 0.0$ \\
\hline & & Literature review & $0 / 0.0$ \\
\hline & & $\begin{array}{l}\text { Other (e.g., theoretical } \\
\text { model; diagnosis manual) }\end{array}$ & $4 / 100.0$ \\
\hline \multicolumn{4}{|l|}{ Publication date } \\
\hline Before 2000 & \multicolumn{3}{|l|}{$17 / 28.3$} \\
\hline After 2000 & \multicolumn{3}{|l|}{$43 / 71.7$} \\
\hline
\end{tabular}

concurrent planes: the beliefs and assumptions that underpin the model, the formulation of problem gambling patterns and some qualifications that augment the formulations within the model. In the first aspect, it is important to note that gambling is viewed as intentional and assumed to have a life enhancing meaning that becomes evident from the current and historical contextual factors. For the second point, the author (Hammond 1997) distinguished three underlying dynamics to explain problem gambling: problem gambling arising from a worldview that is overly competitive, problem gambling as a statement or protest and problem gambling as a way of avoiding pain and distress. The last aspect gives a more complete picture of problem gambling, drawing attention to the dynamic nature of the model, the intergenerational patterns, the life cycle and the contextual issues.

Although this model presents a systemic approach to gambling, its formulations appear poorly integrated and often too focused on the individual angle (the gambler). In this regard, although this model offers added value to the systemic thinking about gambling it still lacks an integrated and systemic approach that concentrates more on relationships to explain this problem.

\section{Conceptual Delimitation of Pathological Gambling}

Gambling can be a continuum of growing psychopathological severity (Ladouceur 2002). Based on this assumption we shall take a fresh look at the various types of gambler and 
then define the concept of pathological gambling and its evolution, particularly in terms of diagnostic classification.

\section{Gambler Typologies}

Depending on the criteria (e.g. motivations, psychological and social traits, consequences), the literature establishes various typologies for people who gamble (Custer and Milt 1985; Darbyshire et al. 2001; González 1989; Kusyszin 1978; Morán 1970; Ochoa and Labrador 1994). They are concerned with the individual, ascribing the problem (or its absence) to individual characteristics and/or motivations.

Of particular interest in this analysis are the typology described by Ochoa and Labrador (1994) (social gambler, professional gambler, problem gambler and pathological gambler) and that proposed by Ladouceur (2002) (low-risk gambler, medium-risk gambler, high-risk gambler and problem gambler) because: (a) they are the most recent and strongly referenced in the literature on PG; (b) they express the continuing nature of the development of the problem, and (c) they are complementary. In the first typology (Ochoa and Labrador 1994), the social gambler gambles for entertainment and spends only small amounts of leisure time and money to the activity; the professional gambler makes a living through gambling and he is characterized by limited risks and discipline; the problem gambler dedicates more time, thoughts, and money to gambling and it also causes problems in his life; the pathological gambler has an uncontrollable preoccupation with and urge to gamble, gambling is the most important thing in his life, leading to severe problems. As regards the second typology (Ladouceur 2002), people in the low-risk category do not develop gambling problems; medium-risk gamblers are individuals who are regular gamblers and may at times gamble more than they should, but their overall gambling pattern is within the no-problem spectrum; high-risk gamblers are at risk of crossing the line and becoming problem gamblers; and problem gamblers are a minority of gamblers who have developed problems. Reconciling these two typologies (Ladouceur 2002; Ochoa and Labrador 1994) and shifting the thrust from the gambler to the relationship with gambling, we built up a new typology of relationships with gambling. This typology is based on the two axes: (1) gambling frequency and (2) the negative consequences of gambling, which together indicate the type of relationship with gambling (Fig. 1). It is underpinned by the presumption that gambling in itself is a recreational activity, such that the degree of pathology that can be linked to it stems from the type of relationship that is built up with it. The behaviours of the subject in each relationship type are associated with her/his personal, family, professional and social traits in the relation with gambling and not associated with these traits per se. Consequently, we emphasize the development and reversibility of these relations through a continuum of (de)(in)creasing severity. This typology is intended to contribute to a more depathologised view of gamblers, thereby encouraging the involvement of their family members and significant others in the process of therapeutic intervention. There are four relationship types: (1) absence of relationship, that is, the person does not gamble or only does so sporadically, with no associated negative consequences; (2) relationship of controlled domination from which the gambler gains recreationally or professionally (e.g. they can stop the activity when they want; gambling has no negative impact on their personal or family life); (3) relationship of partial subordination, established through the domination exerted by gambling on a considerable part of the subject's life, especially in terms of financial matters; (4) finally, relationship of complete subordination where gambling wholly dominates the person, whereby they play a role of total submission that results in a variety of serious problems (family, marital, work 

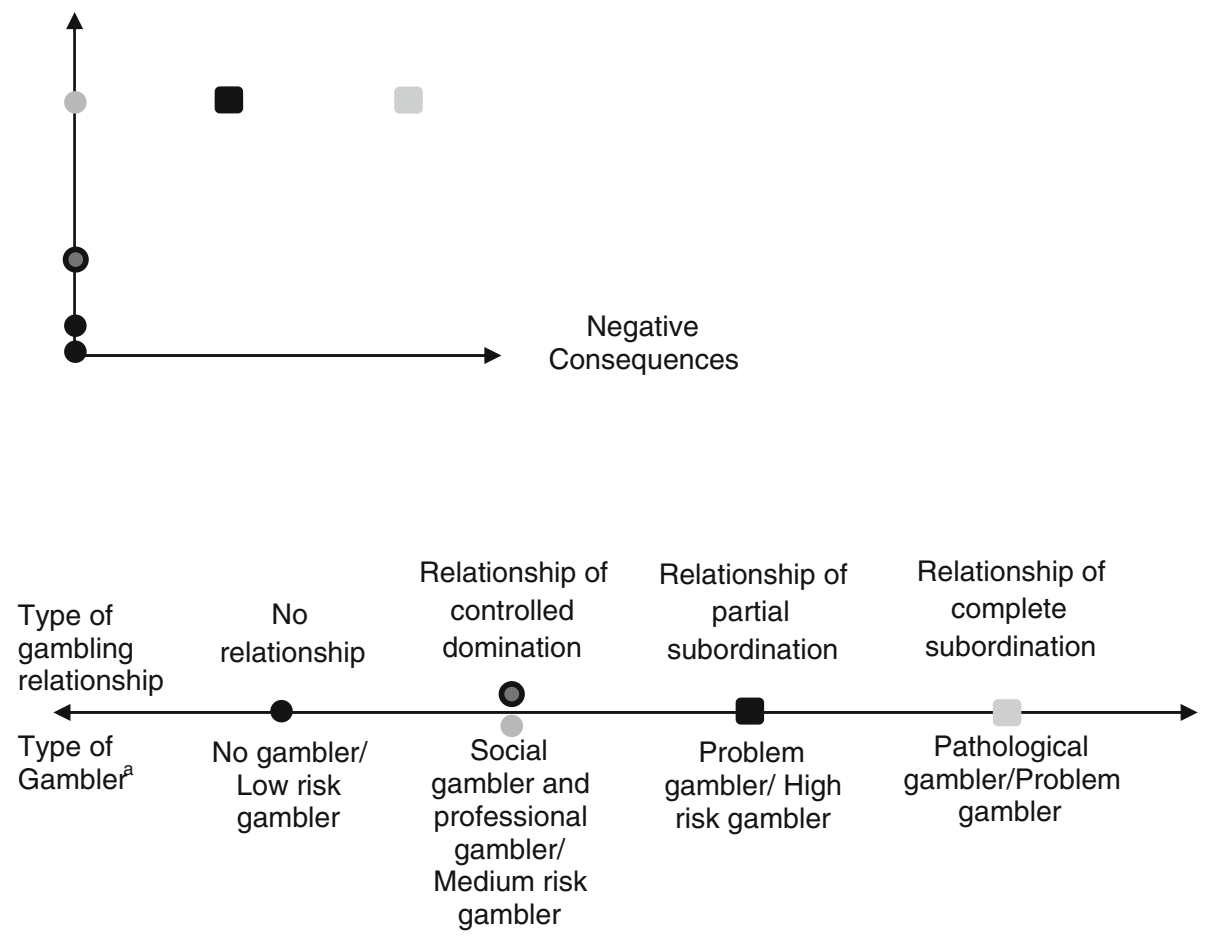

a Based on Ladouceur (2002) and Ochoa and Labrador (1994)

Fig. 1 Relationship typology with gambling

related, financial, physical and mental health, and others). This last relationship type coincides with what the literature tends to designate PG (American Psychiatric Association 2002).

Pathological Gambling and Its Diagnosis

PG is taken as an inadequate behaviour with respect to recurrent and persistent gambling (American Psychiatric Association 2002), characterised by a progressive failure to control the gambling impulse and a gradual deterioration in the personal, family, social and work related domains (Fernández et al. 2002; Martínez et al. 1993), and in the economic and legal ones, too (Oei and Gordon 2008).

Gambling frequency and the amount of money and time spent on it are important indicators of the degree of severity/pathology associated with gambling (Garrido et al. 2004). It is worth summarising the criteria listed in DSM-IV-TR (American Psychiatric Association 2002) to clarify the diagnosis of PG, of which at least five must be observed: (1) concern with gambling (e.g. reliving previous gambling experiences); (2) needing to stake larger amounts of money to achieve the desired level of excitement; (3) failed 
attempts to control, cut down or stop gambling; (4) anxiety or irritability when trying to cut down or stop gambling; (5) gambling can be a form of escape from problems or a way of alleviating a dysphoric mood; (6) repeatedly losing and "hostage" behaviour to try and recover losses; (7) lying to the family, therapist or others about the extent of and involvement in gambling; (8) committing crimes to fund gambling; (9) putting at risk or actually losing significant relationship, jobs or career or academic opportunities because of gambling; (10) relying on others to get money to settle a desperate financial situation brought about by gambling.

Although PG is now accepted by the scientific community as a psychopathological condition it has not always been so. Indeed, this view is relatively recent and still developing. PG only achieved this status in 1980, being classified as an impulse control disorder under DSM-III (American Psychiatric Association 1980). Insofar as the diagnostic criteria for PG were revised in subsequent editions of the DSM [up to DSM-IV-TR (American Psychiatric Association 2002)], the parallels between PG and drug addiction have become obvious. For example, criteria (2), (4) and (9) in DSM-IV-TR (American Psychiatric Association 2002), listed above, relate to three important characteristics of addictive behaviour in generaltolerance, dependence and subordination, respectively. Martínez et al. (1993) define tolerance as a need to increase the amount bet and the frequency of gambling to achieve the desired excitement; dependence is the subjective need to gamble to maintain a state of equilibrium, and subordination is satisfying the overriding need to gamble to the detriment of any other need (e.g. eating, accommodation) for themselves or their family. But there are also some differences: Abbott et al. (1995) believe that in other addictions they are identifiable growing warning signs over a long period as the problem develops. In gambling, until the problem has become well established, there are almost no warning signs and the shift from recreational to pathological gambler may only take a short time.

At any rate, today the similarities between PG and other addictions (e.g., alcoholism) seem to be generally agreed and accepted (Fabionsson 2006; Krishnan and Orford 2002). Even though there is empirical evidence for the association between gambling and impulsive behaviour (Pagani et al. 2010), which bears out the conceptualisation of PG as an impulse control disorder, in the latest classification PG moves from the category Impulse Control Disorder [DSM-IV-TR (American Psychiatric Association 2002)] to a new category called Substance-Related Disorders (American Psychiatric Association 2010)_DSM-V (due to be published in 2013). This is due to the inclusion of "dependence without substance" Disorders through Substance Use in DSM-IV-TR (American Psychiatric Association 2002), whose designation has been changed in response to the expansion of the category and to the international recommendations of participants involved in revising the diagnostics (American Psychiatric Association 2010).

Because of its recent sojourn in the area of mental health, PG is still in the process of having its psychopathological status defined. This can be explained by the explanatory complementarity afforded by the two perspectives-impulse control disorder and dependence. But this last development, which is more conceptual, appears to be generally agreed.

\section{Pathological Gambling and Family}

PG is strongly associated with contextual factors (Griffiths and Delfabbro 2001), and the family is naturally on the list. So family factors are addressed under this point, inasmuch as they are involved in the combination of risk and protection factors with respect to the development of PG (Dickson et al. 2008; Hardoon et al. 2002). The association of family 
and PG is specifically analysed from two angles: first we look at the issue of transgenerationality, and then we consider the relationship dynamics of families, in particular of couples, with PG problems.

\section{Transgenerationality}

'Transgenerationality' has two meanings in this work: (1) transmission of "family rules, beliefs and myths (...) from generation to generation"(Gameiro 2007), which can be related to the development of PG. For example, the significance that the family ascribes to money can be a "predisposing factor" for PG (American Psychiatric Association 2002). In this case there is no need for a history of gambling in the family; (2) direct relationship with gambling behaviour (which is not to say that it is more important), particularly through role-model learning. In this case we have to consider the presence of gambling behaviours within the family. The two components can interact and occur simultaneously. Meanwhile, Magoon and Ingersoll (2006) assessed parental influence using three variables-modelling, attachment and monitoring - and concluded that the first is positively related to gambling behaviour, while the opposite is true of the other two.

So we looked at the studies that support the first meaning of transgenerationality. By examining the influence of the parental factors on behaviours associated with their children's gambling in a hundred and eighty families, Oei and Raylu (2004), found that the cognitions of parents linked to gambling indirectly (through the cognitions of the children linked to gambling) influenced the gambling behaviour of the children. On the whole, parents did not pay attention to the gambling habits of their children and saw them as socially acceptable (Ladouceur et al. 1998). Between 1995 and 2000, however, the knowledge and concern behaviour of parents with respect to their children's gambling evolved in that they paid more heed and took greater care, even though some mistaken conceptions were unchanged or had worsened (Ladouceur et al. 2001).

Some studies reported that the life history of gamblers is often marked by neglect and ill-treatment (e.g. physical, psychological, sexual) in childhood by parents and other carers (Lee 2002; Shaw et al. 2007), and by important losses, rejection and deprivation, which would have led to feelings of powerlessness, with them seeing life as insecure, unpredictable and uncontrollable (Whitman-Raymond 1988). Hardoon et al. (2002) took a sample of two thousand three hundred and thirty-six adolescents and, using the Gambling Activities Questionnaire (GAQ), divided the participants into four groups: non-gamblers (who had not gambled in the past year); social gamblers (who scored 0-1); at-risk gamblers (who scored 2-3), and probable pathological gamblers (who scored 4 or more). The authors' main purpose was to study the relationship between risk and protection factors and the severity of gambling behaviours in adolescence. In terms of family factors they found that adolescent at-risk gamblers and probable pathological gamblers tended to perceive their parents and relatives as "uncaring", "harsh" or over-critical and to feel emotionally detached from them.

In terms of the second meaning of transgenerationality, directly related to gambling, there seems to be plenty of empirical evidence that family history of PG is linked to an increased risk of developing the problem (American Psychiatric Association 2002; Felsher et al. 2003; King et al. 2010; Shaw et al. 2007). Teo et al. (2007) studied a sample of a hundred and fifty pathological gamblers to try and describe their demographic and clinical characteristics: $26.7 \%$ of the participants reported a family history of gambling. Desai et al. (2007) studied gambling behaviours in young people ( $\mathrm{n}=4523$ students) and found that around $23 \%$ of pathological gamblers either had had or still had a close relative whose 
gambling behaviour was worrying or made them afraid, and that $14 \%$ of frequent gamblers had had or still had a close relative with a potential gambling problem. The start of gambling behaviours very often started with relatives. This was shown in a quantitative study ( $\mathrm{n}=477$ children aged 9-14) on social and family factors in which around $81 \%$ of children who gambled reported having started this behaviour with relatives (Gupta and Derevensky 1997). Consistent with these findings, Felsher et al. (2003) reported that around $70 \%$ of one thousand and seventy-two young people who took part in their study, which aimed to assess the relationship between parental involvement in lottery games and its relationship to the young people's learning gambling behaviour, had received a lottery ticket as a gift from parents and friends. Oei and Raylu (2004), in their study (mentioned above), perceived that the gambling behaviour of parents had a direct influence on their children's gambling behaviour. Other authors support these results (Felsher et al. 2003; Lee 2002).

The powerful empirical evidence (American Psychiatric Association 2002; Desai et al. 2007; Felsher et al. 2003; Fernández et al. 2002; Gupta and Derevensky 1997; Hardoon et al. 2002; King et al. 2010; Magoon and Ingersoll 2006; Oei and Raylu 2004; Shaw et al. 2007; Teo et al. 2007), thus enables us to say that gambling behaviours are a part of the transgenerational legacy. It can be related to behaviours, beliefs, thinking, or feelings that may or may not be directly related to PG in the family. Not brushing aside the genetic perspective supported by some authors (Ibáñez et al. 2003), this article focuses essentially on the assumptions underlying the dynamic relationships of families. We therefore concentrated on the role of the parents (1) as an agent in the learning process by providing a role model for gambling behaviours, and (2) as a transmitter of significances (e.g. the significance ascribed to money) or (3) as a developmental context of risk (e.g. an agent of traumatic early experiences). In sum as a context that nurtures the development of the individual, and gambling can be one of the emerging problems.

\section{Family Functioning and Pathological Gambling}

Two aspects should be underscored before focusing on understanding the family functioning of pathological gamblers: (1) it is very hard to be precise about the chronological order of the characteristics of family functioning, before or after the problem, given the transverse nature of the studies in question; (2) gamblers belong to the family with all their facets, which is not made clear in the literature, since they are often portrayed as an external agent of consequences for the family. These considerations do not mean that, as with other addiction problems (e.g. alcoholism), PG may not destroy the whole family system (Krishnan and Orford 2002). This problem is associated with a series of negative effects (e.g. frequent lying, financial problems and desertion of work and family responsibilities) that seriously affect the family, especially the members closest to the gambler (Shaw et al. 2007), as is the case of the nuclear family (marital and filial subsystems) (Darbyshire et al. 2001; Fernández et al. 2002; McComb et al. 2009).

The works that set out to analyse the relationship between PG and gamblers' families came to pretty much the same conclusions. This agreement holds not only for the results of those in which actual gamblers participated (Ladouceur et al. 2004; Suurvali et al. 2010) and for those whose results are yielded by the participation of gamblers' relatives (Kalischuk et al. 2006), and, indeed, for both. PG appears to be associated with relationship issues (Suurvali et al. 2010), specifically family and marital ones (Ladouceur et al. 2004), such as arguments, anger, violence, lies, deception, neglect of the family by the gambler, poor communication and muddled family roles and rules (Kalischuk et al. 2006). 
Alongside these problems, which top the list of difficulties linked to PG, we find financial problems (Kalischuk et al. 2006; Suurvali et al. 2010), followed by negative emotions, problems at work or legal difficulties, and worries about physical health (Suurvali et al. 2010).

Gamblers feeling dissatisfied with the family environment is also obvious (Ciarrocchi and Hohmann 1989), in particular with respect to relationship variables such as family support (Ciarrocchi and Hohmann 1989; Dowling et al. 2009; Hardoon et al. 2002), degree of expressiveness within the family, open expression of anger (Ciarrocchi and Hohmann 1989) and emotional responsiveness (Hardoon et al. 2002). Furthermore, gamblers themselves often display various comorbid psychopathologies (e.g. depression, anxiety) (Teo et al. 2007), and physical (e.g. gastrointestinal disorders, high blood pressure, back and neck pain) or emotional health problems (e.g. desperate need for money, sever depression, guilt, loneliness) (Lorenz and Yaffee 1986).

The experience of the sundry effects of gambling extends, as we have seen, to their significant others, especially to the people who live with gamblers, who also report difficulties ranging from meaningful levels of emotional suffering (e.g. depression) (DicksonSwift et al. 2005) to various physical symptoms (e.g. muscular tension, headaches, stomach ache) (Dickson-Swift et al. 2005). With respect to the filial subsystem, risk to health and well-being in general are described, along with symptoms of depression and behavioural problems (Darbyshire et al. 2001). In the parental subsystem (the gambler's parents) emotional problems emerge in exactly the same way (e.g. fear, guilt, anger) (Moody 1989). But it is at the level of the marital subsystem that these effects are exhibited most abundantly (Lee 2002), so this issue is addressed separately.

\section{The Specificity of the Couple}

When pathological gamblers live with a partner, the marital subsystem is usually the first to notice the effects of the problem (Montero and Megías-Lizancos 2011). Obviously the way the situation-problem is felt by the partner changes with time and, according to Dowling et al. (2009), it goes through specific phases: denial, characterised by lack of awareness of the extent of the problem and attempt to rationalise gambling behaviours; stress, represented by deficient interpersonal communication, greater efforts to repair and "cover up" the damage caused by gambling, social isolation, feelings of frustration and resentment; and the exhaustion phase, when the problem gives rise to somatic illnesses, intense psychological suffering, unsuitable behaviours, unsatisfactory sexual relationship and greater likelihood of seeking professional help.

But the perceptions of pathological gamblers and their spouses or partners about the consequences of the gambling problem do not seem to be the same. This is indicated in an exploratory study (Ferland et al. 2008) ( $n=7$ couples with one pathological gambler partner) which found that couples only agreed about the problems caused by gambling with respect to financial issues. Gamblers' partners tend to mention the consequences of gambling on the gambler's social life more often, while gamblers tend to place more emphasis on the consequences of gambling on their psychological well-being. The outcome of this divergence of views could often lead to married pathological gamblers feeling a lack of help and support, and the absence of a sense of personal independence in the marital relationship (Ciarrocchi and Hohmann 1989).

It is perceived, therefore, that the marital relationship of pathological gamblers is often rocked by a huge, self-reinforced set of problems: fear of the future, dwindling responsibilities of the gambler (Fernández et al. 2002; Lee 2002), unsatisfactory sexual 
relationship, anger and resentment (Fernández et al. 2002; Lee 2002; Lorenz and Yaffee 1986), feelings of guilt, isolation, lack of confidence, loss of respect (Dickson-Swift et al. 2008; Fernández et al. 2002; Lee 2002) and financial problems (Dickson-Swift et al. 2005). Communication tends to break down and separation and divorce are common (DicksonSwift et al. 2005; Fernández et al. 2002; Lorenz and Yaffee 1986; Shaw et al. 2007). Other areas of difficulty of particular importance to couples where one of them is a pathological gambler, are emotional and sexual intimacy, the expression of emotions (Lorenz and Yaffee 1986; Steinberg 1993) and control and power (Steinberg 1993).

Lying and deceit are always factors (Dickson-Swift et al. 2005), engaged in by both the gambler who tries to hide the extent of the problem and the partner who tries to conceal the gambling losses from the rest of the family (Shaw et al. 2007). Bertrand et al. (2008) believe that some behaviours exhibited by spouses and partners in terms of hiding or downplaying the problem (e.g. finding excuses for gamblers missing work, paying debts, avoiding discussions about gambling, taking over the gambler's responsibilities in dealings with creditors or within the family) can contribute to gambling behaviour. We thus get a vicious circle within the marital relationship of pathological gamblers: gamblers feel a growing need to gamble as a reaction to the controlling behaviour of significant others, who, for their part, then try to exert greater control to deal with the gambling problems, and so it goes on (Bertrand et al. 2008). This is how, according to Garrido et al. (2004), gamblers' behaviour turns into one of the vertices of the triangle around which the couple relates, and so the communication about all sorts of other topics (e.g. children's education, sexual relationship, relationship with parents) ends up by be mediated by the presence or absence of gambling. In addition to these realms of marital difficulty some studies indicate the occurrence of violence within couples affected by gambling, with an incidence significantly higher than that for the public in general (Liao 2008).

It seems obvious that, given the complexity of the problems experienced by a couple where one is a pathological gambler, marital contentment would be affected. And a study that analyses the social adjustment, personality and negative emotions of partners of pathological gamblers does suggest that (Mazzoleni et al. 2009). The results of this study show that the wives of pathological gamblers $(n=25)$ exhibit considerable marital dissatisfaction compared with control participants, although they do not show signs of personality disorders or negative affectivity. Dowling et al. (2009) corroborated these data in a study with fifty-three pathological gamblers, twenty-nine spouses and forty children, with the aim of assessing the dyadic and family adjustment of pathological gamblers. They found that both the spouse or partner and the gambler showed poor dyadic adjustment compared with the standardised sample.

Finally, with respect to Portugal, there is a striking dearth of empirical studies on PG, which is even more noticeable when it comes to issues related to the family effects associated with it. But a study by Lopes (2009) found that $22 \%$ of gambling addicts $(n=571)$ got divorced because of the problem. This agrees with what is reported in the international literature on the topic, albeit with a lower percentage. Lorenz and Yaffee (1986), in fact, report a divorce rate of $59 \%$ for couples with gambling problems.

\section{Integrative Systemic Model of Pathological Gambling}

Following the organisation and coordination of the above literature review, a systemic model is now presented that explains and integrates PG, with particular emphasis on the marital subsystem, which makes it possible to understand the development and 
maintenance of PG (Fig. 2). It sets off from a macro-perspective and heads to a microperspective in which all levels of understanding influence one another.

The first level considered is the social context. Aspects such as the social acceptance of gambling behaviours and its availability will naturally influence the development of PG. At this level we would draw attention to the growing accessibility to legal gambling, motivated to a great extent by economic development interests, such as the expansion of legal gambling as a way of stabilising government revenues (Honoré et al. 2007), for instance. This can be seen in the geographic spread and diversification, even online, of gambling locations and products and publicity for them, for example Hing (2002) and Dickson-Swift et al. (2005) reported this in a study that showed that most participants thought that access to legal gambling had a direct bearing on the development of the problem.

On a second level the spotlight falls on the family and the two aspects explained above: transgenerational and relationships. Transgenerationality can be positively or negatively related to $\mathrm{PG}$, directly or indirectly. The first instance involves the transmission of behaviours, thinking, beliefs (etc.), directly related to gambling [e.g. gambling habits within the family (Desai et al. 2007) or downplayed credence of the psychopathological

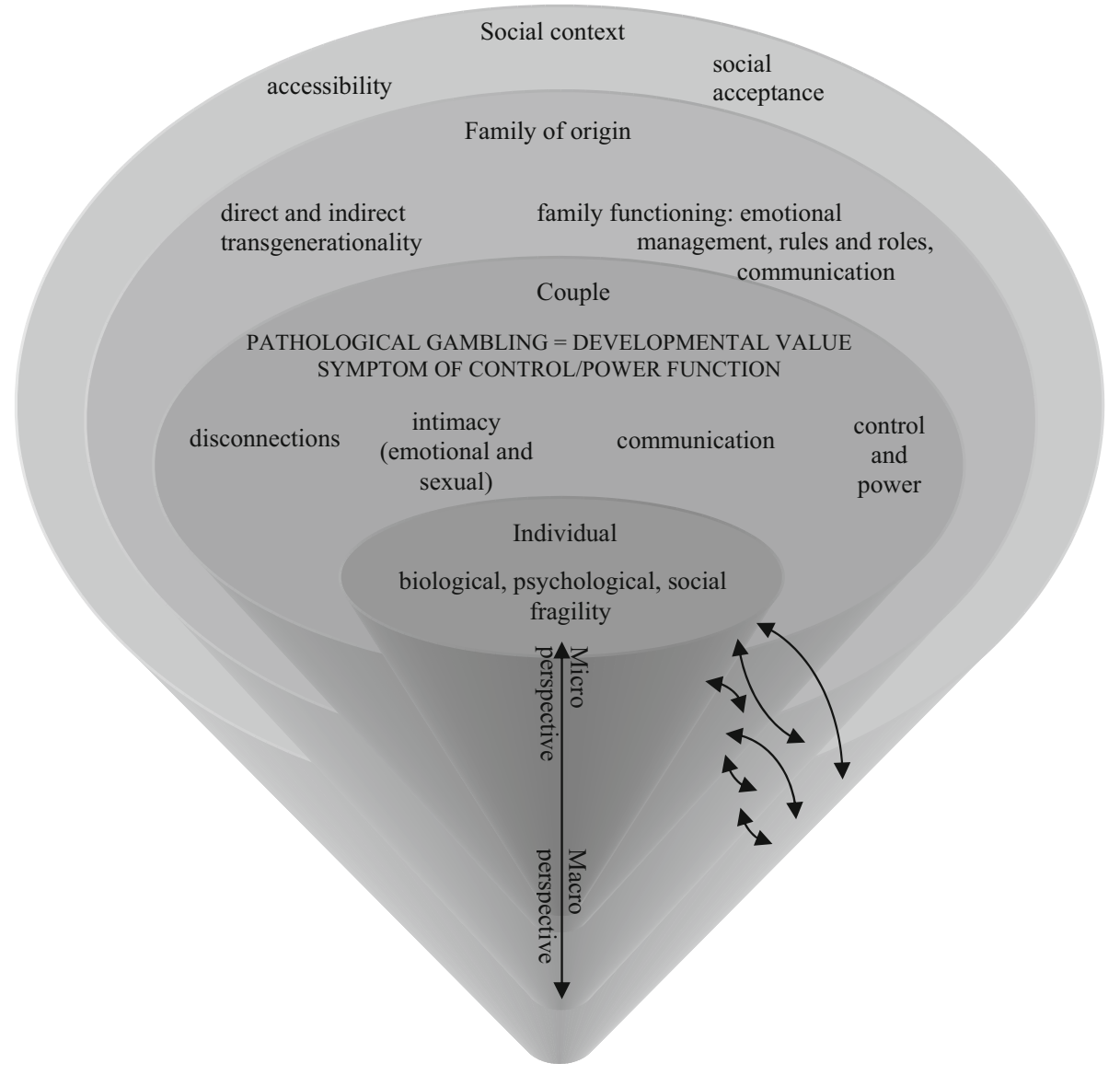

Fig. 2 Integrative systemic model of pathological gambling 
potential of gambling (Ladouceur et al. 1998)]. In the second, the literature review revealed some factors for the development of PG, including ill-treatment in childhood (Lee 2002) and the significance ascribed to money by a gambler's parents (Fernández et al. 2002). In terms of the relationship aspect, i.e. the functioning of the gambler's family, some patterns are associated with the maintenance of PG, inasmuch as, as noted with families with a drug addict member, these families "are not special or unique kinds of family, though they may have features in common" (Relvas 2003). Three major areas of difficulty are noted here: (1) management of emotions and affections, particularly with respect to expressing and communicating them (Ciarrocchi and Hohmann 1989; Kalischuk et al. 2006); (2) unclear family rules and roles (Kalischuk et al. 2006); and (3) communicational poverty, often governed by arguments and lies (Kalischuk et al. 2006). This matrix is associated with the self-perception of these families as being not very supportive and not very emotionally nurturing, which results in strong family dissatisfaction (Dowling et al. 2009; Hardoon et al. 2002).

On a third level, heading in the micro direction, we have the (sub)system on which this model focuses: the couple. The reasons for this emphasis should be explained: (1) the marital subsystem is usually the first to feel the effects of PG (Montero and MegíasLizancos 2011), and (2) it is held to be the subsystem that most affects people over their lives (Relvas, 1996), so that any changes in it have a strong influence on the other family subsystems (Garrido et al. 2004; Lee 2009). These couples' problems with marital functioning are seen in the continuity of the difficulties of their parents. In addition to high marital discontent (Mazzoleni et al. 2009) the literature somewhat redundantly indicates four major areas of difficulty: (1) emotional intimacy (e.g. psychological suffering, anger, guilt, frustration, resentment) (Lorenz and Yaffee 1986; Steinberg 1993) and sexual intimacy (sexual dissatisfaction) (Lorenz and Yaffee 1986); (2) communication (e.g. lying, deceit, attempts to hide or repair damage caused by the problem) (Dickson-Swift et al. 2005); (3) control and power (e.g. violent behaviour, financial matters as the main focus of power struggles) (Steinberg 1993), and (4) detachment, that is, lack of awareness, recognition, acceptance and engagement of the experiences of one partner with the experiences of the other (Lee 2002).

These traits of marital functioning and PG are fed repeatedly. If we develop this idea then a reading of the formation of the PG symptom can be made, focused on the marital subsystem. Assuming (1) that it is not the system that indicates the symptom, but that one behaviour, from an infinite set of other possible ones, will have an impact that it would not have if the system had not already been in difficulties, and (2) the notion of developmental value of the symptom (Ausloos 2003), gambling would be a sign of something wrong in one or more vital functions of the marital subsystem. Bearing in mind the characteristics of a marital relationship listed earlier (which, as we mentioned, are linked in a bond of continuity with those of the families), the exercise of control and power in the relationship can be indicated as one of those functions. This conceptualisation makes sense when the feeling of personal independence is missing from the marital relationship, as the gamblers report (Ciarrocchi and Hohmann 1989), and the importance of "detachment" in these couples (Lee 2002). In other words, gamblers feel that their "Self" is worthless, scarcely understood within the relationship, and so they can find in gambling an activity that engenders an illusory sensation of power. However, since the spouse or partner also sees this behaviour as a relevant item in defining the power relationship within the partnership/ marriage, this activity tends to be repeated and extended and the two parties focus on it (selection-extension process). The fears, anxieties and dreads often transmitted transgenerationally (e.g. the dread that, as happened with other family members, gambling will turn 
out to be a problem, or the anxiety caused by the value the couple places on money) and the crises and high levels of stress within the system (Lee 2002) reinforce this recursive, dyadic process. Gambling behaviour then becomes a habit and, as it crystallises (Ausloos 2003), becomes pathological by replacing/triangulating one of the functions of the system (the exercise of control/power in the relationship).

In brief, gambling let gamblers to rediscover their own space to satisfy their need for control and power, and enables their spouse or partner to do exactly the same. So the latter will activate a series of strategies to minimise the consequences of the problem (trying to conceal it from the rest of the family, taking over the gambler's family and work responsibilities, getting money for the couple, and so forth). This underscores the power imbalance, however, and leads the gambler to extend his/her behaviour in response to the control exerted. So we have a hidden symmetry based on gaining power in the relationship, and this becomes a self-reinforcing vicious cycle that keeps the problem going. By this reasoning it is assumed that most of the marital problems reported in the literature as consequences of PG (e.g. difficulties in communicating and expressing affection; unsatisfactory sexual relationship) can precede it (Lee 2002). But of course this fact does not invalidate the possibility of it worsening after crystallisation (Ausloos 2003) of the gambling behaviour.

Finally, the last level of the analysis, and the most "micro" is the individual, where factors ranging from personality traits (impulsiveness, lack of control, etc.) (American Psychiatric Association 2002) to aspect such as neuro-cerebral function are considered (Ibáñez et al. 2003). Furthermore, it should also be considered that some studies (Lee 2002) indicate that the start of a gambling problem may coincide with highly stressful landmarks in a gambler's life, such as emigration/immigration, loss, change of job or demotion, financial setback, health problems, transitions in the life-cycle (marriage, birth of first child, retirement) that leave the person in a more psycho-socially fragile state.

Personal disposition and traits can enhance or reduce the impact of family relationship patterns and vice versa, such as social influences (e.g. positive or negative assessment of gambling), accessibility of gambling (e.g. geographical) and biological factors (e.g. neural transmissions) play an important part in the multi-dimensional functioning of gambling. In fact, all these levels interact with one another, repeatedly. It is easy to see how, in a social context of acceptance and geographic facility, for example, personal weakness may interact with difficulties of defining the power relationship in a partnership/marriage and with transgenerational aspects favourable to the development of PG and thus facilitate the symptom selection process explained above.

\section{Conclusion}

We have proposed in this article that the degree of psychopathology associated with gambling depends on the relationship that gamblers establish with the activity. This is strongly related to the quality of the gambler's marital relationship (Lee 2002), as the explanatory integrative model of gambling, presented above, makes clear. It thus seems essential that the family, particularly the couple, are included in both the comprehensive and therapeutic approaches to PG (Steinberg 1993).

\section{Limitations}

The model presented proposes an integrative approach based on a variety of works (Table 1), including theoretical models, literature reviews, empirical studies (with different 
experimental designs). Although, on the one hand, this enriches the conclusions drawn, on the other hand it makes it harder to accurately compare the results/evidence, hindering a choice, for example, between two incompatible/contradictory results. It is also felt that PG and the family/couple is an "immature" topic in the literature, with few studies and small samples (not representative). In addition, even those studies that do consider aspects of family functioning, they are mostly based on uni or bi-directional relationships, ignoring the idea of circularity. Furthermore, the transversal character of PG is not compatible with the cause-effect logic presented in some studies. We believe that the idea of a relationship/ association between the variables (gambling and family/couple) is more appropriate.

\section{Future Directions}

It seems essential that future studies should continue examining PG from a systemic familiar perspective. The empirical validation of the systemic models (comprehensive/ explanatory and interventional) relating to PG is therefore a matter of urgency, especially with respect to the marital subsystem. This is, moreover, a tendency which is currently beginning to attract attention in some countries such as Canada, by developing couple therapy models adapted to pathological gamblers (Bertrand et al. 2008; Lee 2009). In terms of their efficiency, the few studies that are available (using very small samples and of an exploratory nature), have yielded quite favourable results (Lee 2009), showing the need for empirical validation.

\section{References}

Hardoon' K.' Derevensky“ J.' \& Gupta' R. (2002). An examination of the influence of familial' emotional conduct and cognitive problems' and hyperactivity upon youth risk-taking and adolescent gambling problems. Report prepared for the Ontario Problem Gambling Research Centre.

Abbott, D., Cramer, S., \& Sherrets, S. (1995). Pathological gambling and the family: Practice implications. Families in Society, 76(4), 213-219.

American Psychiatric Association. (1980). Diagnostic and statistical manual of mental disorders (3rd ed.). Washington, DC: Author.

American Psychiatric Association. (2002). Diagnostic and statistical manual of mental disorders (4th ed., text rev.). Washington, DC: Author.

American Psychiatric Association. (2010). America Psychology Association: DSM-V developement. Disponível em http://www.dsm5.org/Pages/Default.aspx Accessed 2011 January.

Ausloos, G. (2003). A competência das famílias: Tempo, Caos, Processo (2nd ed.). Lisboa: Climepsi Editores.

Bertrand, K., Dufour, M., Wright, J., \& Lasnier, B. (2008). Adapted couple therapy (ACT) for pathological gamblers: A promising avenue. Journal of Gambling Studies, 24, 393-409.

Ciarrocchi, J., \& Hohmann, A. (1989). The family environment of married male pathological gamblers, alcoholics, and dually addicted gamblers. Journal of Gambling Behavior, 5(4), 283-291.

Custer, R., \& Milt, H. (1985). When luck runs out. Help for compulsive gamblers and their families. New York: Facts on File Publications.

Darbyshire, P., Oster, C., \& Carrig, H. (2001). Children of parent(s) who have a gambling problem: a review of the literature and commentary on research approaches. Health and Social Care in the Community, 9(4), 185-193.

Desai, R., Potenza, M., Krishnan-Sarin, S., Cavallo, D. (2007). Gambling behavior among high school students in the state of Connecticut. Research report delivered to CT Department of Mental Health and Addiction Services and CT Department of Education.

Dickson, L., Derevensky, J., \& Gupta, R. (2008). Youth gambling problems: An examination of risk and protective factors. International Gambling Studies, 8(1), 25-47.

Dickson-Swift, A., James, E. \& Kippen, S. (2005). The experience of living with a problem gambler: Spouses and partners speak out. Journal of Gambling Issues, 13. doi: 10.4309/jgi.2005.13.6. 
Dowling, N., Smith, D., \& Thomas, T. (2009). The family functioning of female pathological gamblers. International Journal of Mental Health and Addiction, 7, 29-44.

Fabionsson, C. (2006). Recreational gambling. Young people's gambling participation in rural Australia. Journal of Youth Studies, 9(3), 345-360.

Felsher, J., Derevensky, J., \& Gupta, R. (2003). Parental influences and social modeling of youth lottery participation. Journal of Community and Applied Social Psychology, 13, 361-377.

Ferland, F., Fournier, P., Ladouceur, R., Brochu, P., Bouchard, M., \& Pâquet, L. (2008). Consequences of pathological gambling on the gambler and his spouse. Journal of Gambling Issues, 22, 219-229.

Fernández, M., Rincón, P., \& Álvarez, A. (2002). Relaciones de pareja y juego patológico: Um estúdio descriptivo a través de la Escala de Ajuste Diádico (DAS). Apuntes de Psicologia, 20(1), 33-48.

Gameiro, J. (2007). Entre marido e mulher...Terapia de casal. Lisboa: Trilhos.

Garrido, M., Jaén, P., \& Domínguez, A. (2004). Ludopatía y relaciones familiares: Clínica y tratamiento. Barcelona: Paidós.

González, A. (1989). Juego patológico: Una nueva adicción. Madrid: Canal Comunicaciones.

Griffiths, M., \& Delfabbro, P. (2001). The biopsychosocial approach to gambling: Contextual factors in research and clinical interventions. Journal of Gambling Issues, 5, 1-33.

Gupta, R., \& Derevensky, J. (1997). Familial and social influences on juvenile gambling behavior. Journal of Gambling Studies, 13(3), 179-192.

Hammond, G. (1997). Problematic gambling patterns: Approaching a systemic view. Australian And New Zealand Journal of Family Therapy, 18(4), 203-209.

Hing, N. (2002). The emergence of problem gambling as a corporate social issue in Australia. International Gambling Studies, 2(1), 101-122.

Honoré, P., Simões, E., Moonesinghe, R., Wang, X., \& Brown, L. (2007). Evaluating the ecological association of casino industry economic development on community health status: A natural experiment in the Mississipi Delta Region. Journal of Public Health Management \& Practice, 13(2), 214-222.

Ibáñez, A., Blanco, C., Perez de Castro, I., Fernandez-Piqueras, J., \& Sáiz-Ruiz, J. (2003). Genetics of pathological gambling. Journal of Gambling Studies, 19, 11-22.

Kalischuk, R., Nowatzki, N., Cardwell, K., Klein, K., \& Solowoniuk, J. (2006). Problem gambling and its impact on families: A literature review. International Gambling Studies, 6(1), 31-60.

King, S., Abrams, K., \& Wilkinson, T. (2010). Personality, gender, and family history in the prediction of college gambling. Journal of Gambling Studies, 26, 347-359.

Krishnan, M., \& Orford, J. (2002). Gambling and the family: From the stress-coping-support perspective. International Gambling Studies, 2, 61-83.

Kusyszin, I. (1978). "Compulsive" gambling: The problem of definition. International Journal of Addictions, 37, 1095-1101.

Ladouceur, R. (2002). Understanding gambling and problem gambling: A step in the right direction. Lecture Series, 1(1), 1-10.

Ladouceur, R., Jacques, C., Ferland, F., \& Giroux, I. (1998). Parents' attitudes and knowledge regarding gambling among youths. Journal of Gambling Studies, 14, 83-90.

Ladouceur, R., Sylvain, C., Sévigny, S., Poirier, L., Brisson, L., Dias, C., et al. (2004). Caractéristiques des joueurs excessifs selon le mode de traitement. Québec: Université Laval.

Ladouceur, R., Vitaro, F., \& Côté, M.-A. (2001). Parents' attitudes, knowledge, and behavior toward youth gambling: A five-year follow-up. Journal of Gambling Studies, 17, 101-116.

Lee, B. (2002). Well-being by choice not by chance: An integrative system-based couple treatment model for problem gambling. Research report submitted to Ontario Problem Gambling Research Center, April 2002.

Lee, B. (2009). Congruence couple therapy for pathological gambling. Mental Health Addiction, 7, 45-67.

Liao, M. (2008). Intimate partner violence within the Chinese Community in San Francisco: Problem gambling as risk factor. Journal of Family Violence, 26, 671-678.

Lopes, H. (2009). Epidemiologia de dependência de jogo a dinheiro em Portugal, disponível em http://www.jogoremoto.pt/watchdog.php?id=16\&sec=5 [accessed on 2010 August].

Lorenz, V. C., \& Yaffee, R. A. (1986). Pathological gambling: Psychosomatic, emotional and marital difficulties as reported by the gambler. Journal of Gambling Behavior, 2(1), 40-49.

Magoon, M., \& Ingersoll, G. (2006). Parental, modeling, attachment, and supervision as moderators of adolescent gambling. Journal of Gambling Studies, 22, 1-22.

Martínez, J., Navarro, C., \& Romero, J. (1993). Trastornos asociados al juego patológico. Anales de Psicologia, 9(1), 83-92.

Mazzoleni, M., Gorenstein, C., Fuentes, D., \& Tavares, H. (2009). Wives of pathological gamblers: Personality traits, depressive symptoms and social adjustment. Revista Brasileira de Psiquiatria, 31(4), 332-337. 
McComb, J. L., Lee, B. K., \& Sprenkle, D. H. (2009). Conceptualizing and treating problem gambling as a family issue. Journal of Marital and Family Therapy, 35(4), 415-431.

Montero, J., \& Megías-Lizancos, F. (2011). El paciente ludópata: dificultades em la família y su entorno social. Artigo apresentado no Décimo Segundo Congresso Virtual de Psiquiatria Interpsiquis, disponível em. http://www.bibliopsiquis.com/biblio psiquis/bitstream/1 0401/2 399/1/11m2conf 65071 4.pdf Accessed on 2011 February.

Moody, G. (1989). Parents of young gamblers. Journal of Gambling Behavior, 5(4), 313-320.

Morán, E. (1970). Varieties of pathological gambling. British Journal of Psychiatry, 116, 593-597.

Ochoa, E., \& Labrador, F. J. (1994). Juego patológico. Barcelona: Plaza \& Janés.

Oei, T., \& Gordon, L. (2008). Psychosocial factors related to gambling abstinence and relapse in members of Gamblers Anonyms. Journal of Gambling Studies, 24, 91-105.

Oei, T., \& Raylu, N. (2004). Family influence in offspring gambling: a cognitive mechanism for transmission of gambling behavior in families. Psychological Medicine, 34, 1278-1288.

Pagani, L., Derevensky, J., \& Japel, C. (2010). Does early emotional distress predict later child involvement in gambling? The Canadian Journal of Psychiatry, 55(8), 507-513.

Relvas, A. P. (1996). O ciclo vital da família. Perspectiva sistémica. Porto: Edições Afrontamento.

Relvas, A. P. (2003). Por detrás do espelho. Da teoria à prática com a família (2a ed.). Coimbra: Quarteto.

Shaw, M., Forbush, K., Schlinder, J., Rosenman, E., \& Black, D. (2007). The effect of pathological gambling on families, marriages and chindren. CNS Spectrums, 12(8), 615-622.

Steinberg, M. A. (1993). Couples treatment issues for recovering male compulsive gamblers and their partners. Journal of Gambling Studies, 9(2), 153-167.

Suurvali, H., Hodgins, D., \& Cunningham, J. (2010). Motivators for resolving or seeking help for gambling problems: A review of the empirical literature. Journal of Gambling Studies, 26, 1-33.

Teo, P., Mythily, S., Anantha, S., \& Winslow, M. (2007). Demographic and clinical features of 150 pathological gamblers referred to a community addictions program. Annals Academy of Medicine, 36(3), 165-168.

Toneatto, T., \& Ladouceur, R. (2003). Treatment of pathological gambling: a critical review of the literature. Psychology of Addictive Behaviors, 17, 284-292.

Toneatto, T., \& Millar, G. (2004). Assessing and treating problem gambling: Empirical status and promising trends. Canadian Journal of Psychiatry, 49, 517-525.

Whitman-Raymond, R. (1988). Pathological gambling as a defense against loss. Journal of Gambling Behavior, 4(2), 99-109. 